\title{
Layered Double Hydroxides as Bifunctional Catalysts for the Aryl Borylation under Ligand-Free Conditions
}

\author{
Lorenna C. L. L. F. Silva ${ }^{1}$, Vinícius A. Neves ${ }^{1}$, Vitor S. Ramos ${ }^{2}$, Raphael S. F. Silva ${ }^{3}$, \\ José B. de Campos ${ }^{2}$, Alexsandro A. da Silva ${ }^{4}$, Luiz F. B. Malta ${ }^{1, *(D)}$ and Jaqueline D. Senra ${ }^{1,4, *}$ \\ 1 Laboratório de Química Supramolecular e de Sólidos, Instituto de Química, Universidade Federal do Rio de \\ Janeiro, Rio de Janeiro 21941-909, Brazil; lorennaconti97@gmail.com (L.C.L.L.F.S.); \\ alevato.v@gmail.com (V.A.N.) \\ 2 Faculdade de Engenharia, Universidade do Estado do Rio de Janeiro, Rio de Janeiro 20550-900, Brazil; \\ vramos00@gmail.com (V.S.R.); brantjose@gmail.com (J.B.d.C.) \\ 3 Instituto Federal do Rio de Janeiro, Campus Rio de Janeiro, Rio de Janeiro 20270-021, Brazil; \\ raphael.silva@ifrj.edu.br \\ 4 Instituto de Química, Universidade do Estado do Rio de Janeiro, Rio de Janeiro 20550-900, Brazil; \\ alexsandro.silva@uerj.br \\ * Correspondence: lfbmalta@iq.ufrj.br (L.F.B.M.); jaqueline.senra@uerj.br (J.D.S.); \\ Tel.: +55-21-3938-7738 (L.F.B.M.); +55-21-2334-0563 (J.D.S.)
}

Received: 29 January 2019; Accepted: 18 March 2019; Published: 27 March 2019

\begin{abstract}
Organic derivatives of boron, such as boronic esters and acids, are important precursors for a wide range of environmental, energy, and health applications. Several catalytic methods for their synthesis have been reported, even though with the use of toxic and structurally complex ligands. Herein, we demonstrate preliminary studies envisaging the synthesis of boronic esters from an inexpensive catalytic system based on $\mathrm{Cu} / \mathrm{Al}$ layered double hydroxides (LDH) in the presence of $\mathrm{Na}_{2} \mathrm{PdCl}_{4}$. The $\mathrm{Cu} / \mathrm{Al} \mathrm{LDH}$ were prepared according to coprecipitation method and characterized by X-ray diffraction (XRD) (with Rietveld refinement) to evaluate the contamination with malachite and other phases. Preliminary catalytic results suggest that pure $\mathrm{Cu} / \mathrm{Al} \mathrm{LDH}$ has potential for the borylation of aryl iodides / bromides in the absence of base. Indeed, a synergic effect between copper and palladium is possibly related to the catalytic efficiency.
\end{abstract}

Keywords: boronic esters; borylation; Suzuki-Miyaura; layered double hydroxides; copper; palladium

\section{Introduction}

Organoboron compounds have received great attention in last years due to significant impact in analytical [1], technological [2], and medicinal fields [3]. Particularly, low-weight compounds containing boronic acid/ester moieties have played an important role in the synthesis of new hybrid materials, sensors and complex organic molecules, through synthetic protocols such as Suzuki-Miyaura reactions. However, mild and selective synthesis of boronic acids and esters still represent a challenge. In general, the classic reactions involving the generation of organometallics (e.g., arylmagnesium or aryllithium) followed by the reaction with a borate have been substituted by catalytic protocols [4]. Recently, new methods involving metal-free conditions have also been discovered [5,6]. However, most of them suffer from low reactivity/selectivity along with relatively high costs of the boron reagents. Some advantages of the catalytic protocols are the improved reaction selectivity and the possibility of the whole system reuse. Since the general steps for the catalytic synthesis of boronic acids and esters involve a sequence of oxidative addition and reductive elimination, several 
semihomogenous or heterogeneous systems are described based on the employment of noble metals (e.g., Pd and Ir) as catalysts [7].

In 1995, Miyaura first reported the Pd-catalyzed aryl borylation protocol by using a phosphine-based catalyst- $\mathrm{Pd}(\mathrm{dppf}) \mathrm{Cl}_{2}$-in the presence of KOAc for the activation of diboron reagent [8]. Since then, several efficient methodologies have been reported based on similar reaction conditions [9-11]. Recently, Ratniyom and coworkers [12] reported an efficient cooperative catalysis based on $\mathrm{Pd}(0) / \mathrm{Cu}(\mathrm{I})$ in the presence of triphenylphosphine with good results towards aryl iodides and bis(pinacolate)diboron. However, the yields were very sensitive to the nature of the base and reduced drastically with the use of aryl bromides/chlorides.

Inorganic networks with basic properties represent one alternative to avoid the use of expensive ligands as well as strong bases in order to achieve the B-B bond activation. Mostly, bimetallic systems usually involve low loadings of a noble metal in combination with an early transition metal to allow a cost-effective, broader functional group tolerance, and scalable reaction condition. Layered double hydroxides (LDHs) — anionic clays also known as hydrotalcites—have a structure based on layers of bi- and trivalent metals hydroxides and interlayer spaces occupied by anions and neutral molecules [13], see Figure 1. They can be composed of a wide range of different metals and anions, which make them useful as anionic exchangers, flame retardants, catalysts, and supports for metallic nanoparticles [14], and have low-cost of synthesis and basic surface properties [15]. Silva and coworkers [16] previously reported a catalyst system based on Mg/Al LDHs, PdNPs, and cyclodextrins for the efficient Suzuki-Miyaura reaction between aryl bromides and arylboronic acids. Lately, Sreedhar [17] employed Cu/Al LDHs as catalysts in Ullmann reactions between aryl chlorides and amines. So far, cross-coupling with heterogeneous ligand-free $\mathrm{Cu}$ (II) based cocatalysts has not been reported to date in borylation reactions.

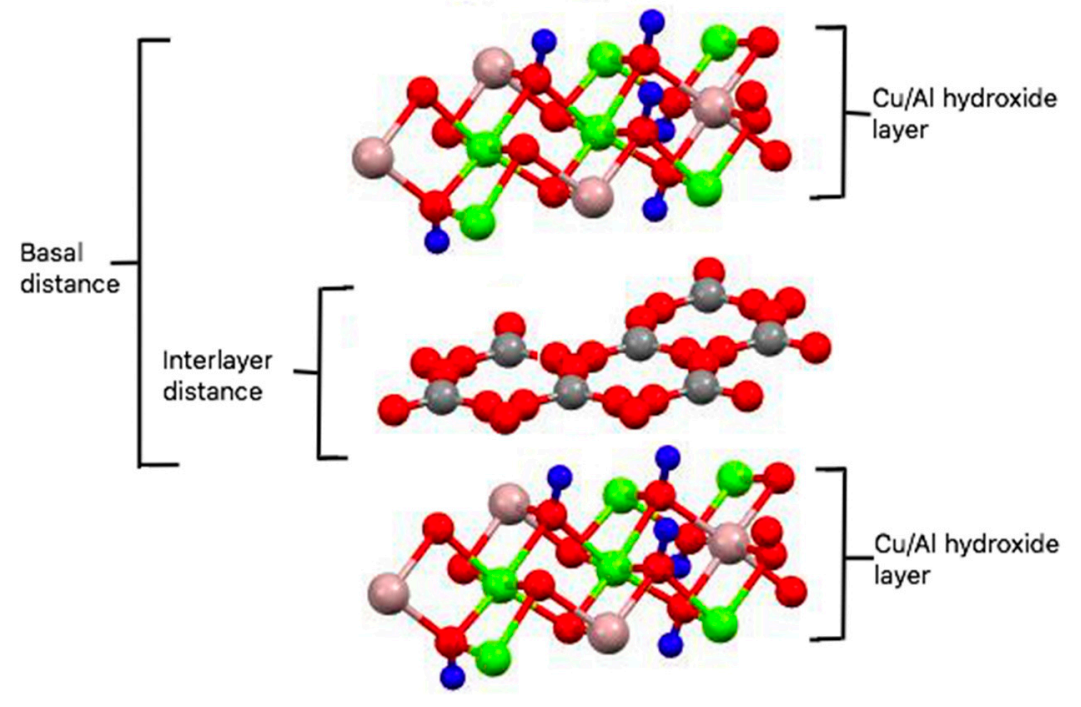

Figure 1. Representation of layered double hydroxide (LDH) hydrotalcite-like structure, with the $\mathrm{Cu} / \mathrm{Al}$ hydroxide layers and the carbonate containing interlayer space. $\mathrm{Cu} \rightarrow$ green, $\mathrm{O} \rightarrow$ red, $\mathrm{H} \rightarrow$ blue, $\mathrm{C} \rightarrow$ grey, $\mathrm{Al} \rightarrow$ light red.

In the present work, we disclosed $\mathrm{Cu} / \mathrm{Al} \mathrm{LDHs}$ as bifunctional cocatalysts in the presence of $\mathrm{Na}_{2} \mathrm{PdCl}_{4}$ for the borylation reactions between aryl halides and bis(pinacolato)diboron. The key points examined here are the influence of LDH purity and the catalytic conditions towards the reaction outcome. 


\section{Results}

\subsection{Synthesis and Characterization of $\mathrm{Cu} / \mathrm{Al} \mathrm{LDH}$}

A set of conditions were varied to accomplish the synthesis of the $\mathrm{Cu} / \mathrm{Al} \mathrm{LDH}$. Figure 2 shows the X-ray diffraction (XRD) patterns of samples obtained using or not sodium carbonate as an additive. These diffractograms were refined using the Rietveld method in order to obtain the composition of phases. In addition, the refinement also afforded the unit cell parameters for LDH phase: these data are available in the supporting information file (Tables S1-S4). The LDH synthesized without sodium carbonate (Figure 2a) exhibited a XRD pattern composed of reflections from the mineral-like phases of gerhardtite $\left(\mathrm{Cu}(\mathrm{OH}) \mathrm{NO}_{3}\right.$, JCPDS-ICDD 01-082-1991), hydrotalcite $\left(\mathrm{Mg}_{0.67} \mathrm{Al}_{0.33}(\mathrm{OH})_{2}\right)\left(\mathrm{CO}_{3}\right)_{0.165}\left(\mathrm{H}_{2} \mathrm{O}\right)_{0.48}$, JCPDS-ICDD 01-089-5434), and nitratine $\left(\mathrm{NaNO}_{3}\right.$, JCPDS-ICDD 00-036-1474). The LDH phase was obtained as a low crystallinity, minority phase with wide and low intensity peaks at $9.7^{\circ}$ and $19.9^{\circ}$. The $\mathrm{Cu}(\mathrm{OH}) \mathrm{NO}_{3}$ phase (gerhardtite) was obtained as the majority phase with the most intense peaks at $12.7^{\circ}, 25.6^{\circ}, 33.9^{\circ}, 36.1^{\circ}, 40.4^{\circ}$, and $42.9^{\circ}$. Finally, $\mathrm{NaNO}_{3}$ (nitratine) was found as another minority phase, however showing a thin peak at $2 \theta=22.8^{\circ}$, besides $29.4^{\circ}, 31.8^{\circ}$, and $38.9^{\circ}$.

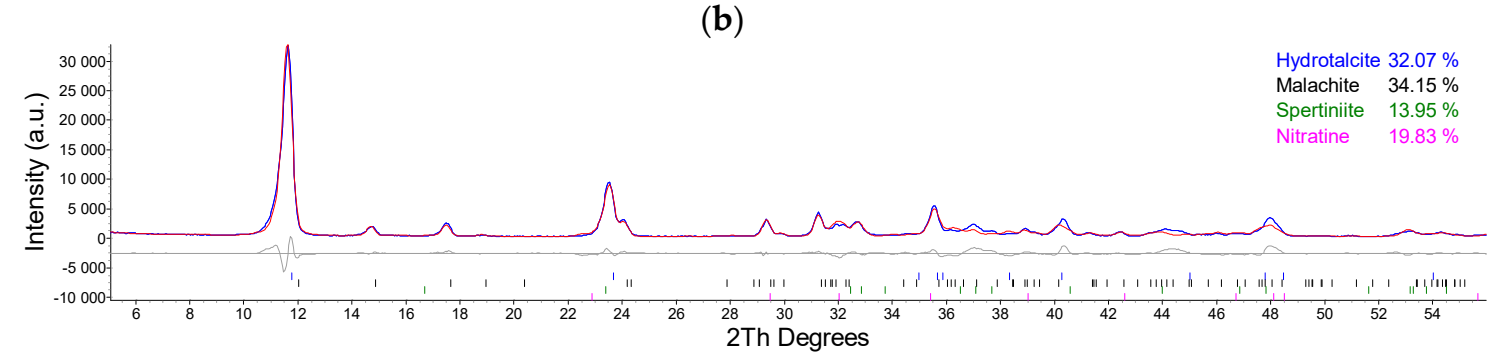

(a)

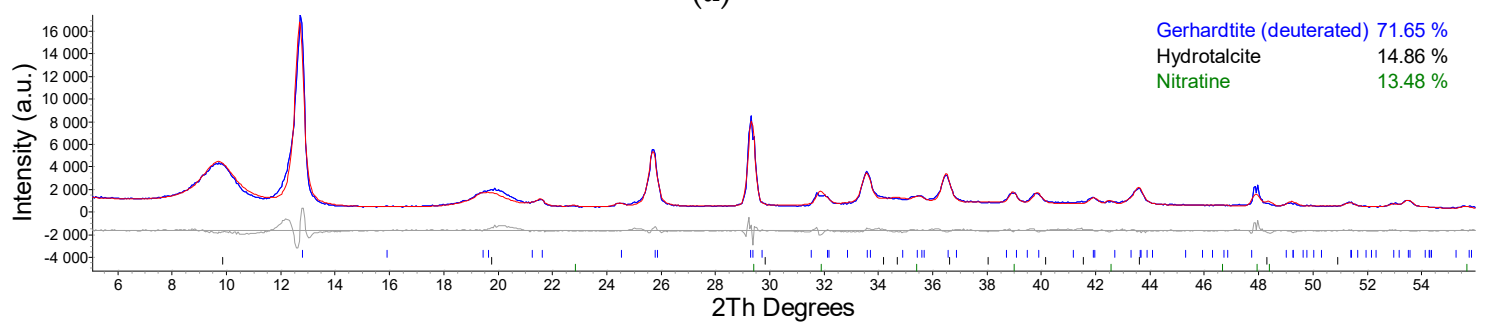

Figure 2. Rietveld-refined X-ray diffraction (XRD) patterns for $\mathrm{Cu} / \mathrm{Al} \mathrm{LDH}$ obtained (a) without and (b) with $\mathrm{Na}_{2} \mathrm{CO}_{3}$ dissolved in the precipitation agent solution.

In contrast, Figure $2 \mathrm{~b}$ shows the XRD pattern for the sample synthesized using sodium carbonate. In this case, the majority phase was the layered double hydroxide with peaks at $2 \theta=11.6^{\circ}, 23.5^{\circ}, 35.6^{\circ}$, $39.5^{\circ}$, and $47.0^{\circ}$. Another significant phase was malachite $\left(\mathrm{Cu}_{2}(\mathrm{OH})_{2} \mathrm{CO}_{3}\right.$, JCPDS-ICDD 01-075-1163) related to the peaks $2 \theta=11.9^{\circ}, 14.7^{\circ}, 17.5^{\circ}, 24.0^{\circ} 29.7^{\circ}, 31.7^{\circ}, 32.6^{\circ}$, and $35.4^{\circ}$. As minority phases, it was found that spertiniite $\left(\mathrm{Cu}(\mathrm{OH})_{2}\right.$ JCPDS-ICDD 01-080-0656) related to peaks at $2 \theta=16.7^{\circ}, 23.8^{\circ}$, $34.0^{\circ}, 35.9^{\circ}$, and $39.8^{\circ}$, and nitratine with peaks at $2 \theta=22.8^{\circ}, 29.4^{\circ}, 31.8^{\circ}$ and $38.9^{\circ}$.

Regarding the LDH unit cell parameters (Table S1, supporting information), both XRD were refined as having a rhombohedral crystal system and belonging to the R-3m spatial group. However, the sample synthesized without carbonate presented the biggest unit cell dimensions $(\mathrm{a}=3.039 \AA$ and $\mathrm{c}=26.921 \AA$ against $\mathrm{a}=2.979 \AA$ and $\mathrm{c}=22.519 \AA$ for the carbonate $\mathrm{Cu} / \mathrm{Al} \mathrm{LDH})$, which means that an expanded structural network was obtained.

The addition of sodium carbonate to the reaction medium allowed obtaining LDH as the main phase, but did not avoid forming malachite, a by-product. Still, it was decided to use the carbonate salt dissolved in the precipitation agent solution in the fore coming tests. 
In the next set of experiments the $\mathrm{LDH}$ precipitation $\mathrm{pH}$ and postsynthesis work-up were evaluated.

The precipitation $\mathrm{pH}$ was varied between two values, 8 and 10, which are the most used in LDH synthesis. The XRD patterns for both samples are presented in Figure 3. Figure 3a evidences the refined XRD pattern for the $\mathrm{LDH}$ precipitated at $\mathrm{pH}=8$, which, compared to that of Figure $3 \mathrm{~b}$, related to $\mathrm{LDH}$ precipitated at $\mathrm{pH}=10$; thus $\mathrm{pH}$ is not a significant parameter in the synthesis. This is also supported by strong similarities of unit cell dimensions between these two samples (Table S2, supporting information). Therefore, a pH of 8 was chosen as the working $\mathrm{pH}$ in the next tests.

(b)

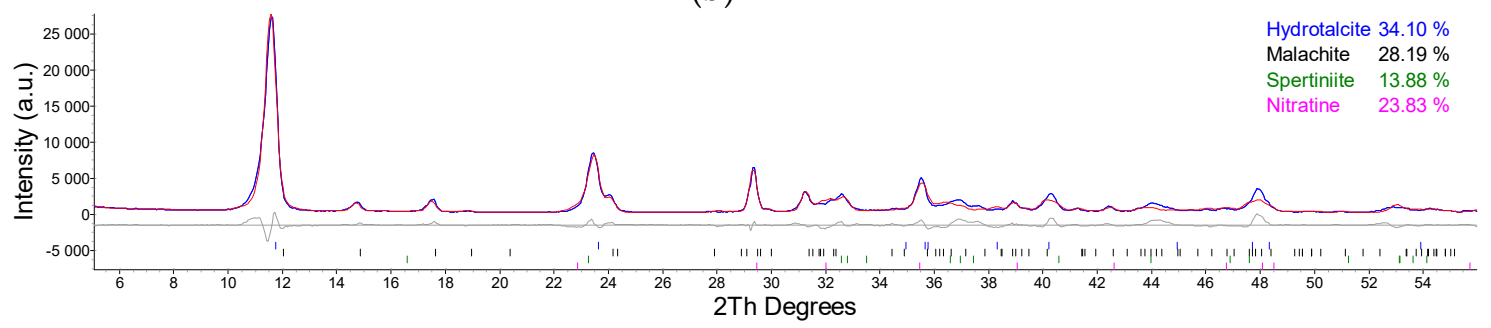

(a)

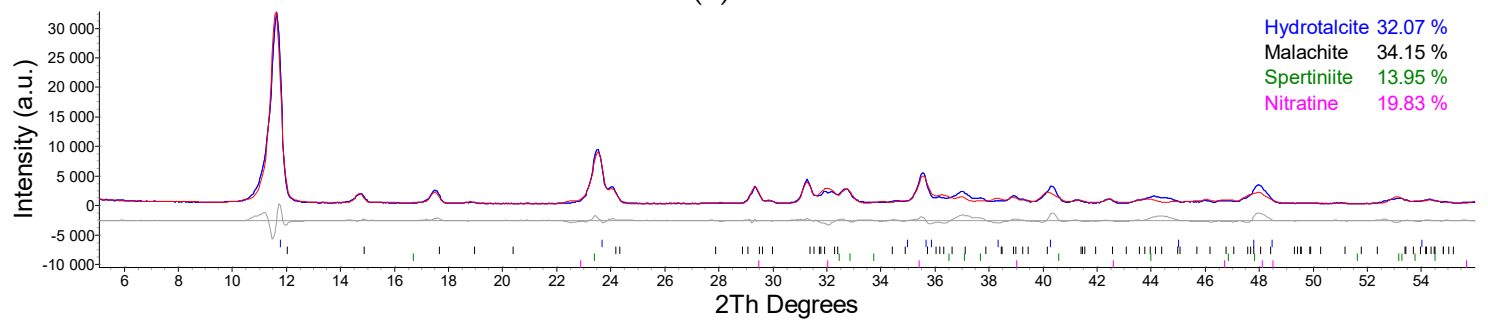

Figure 3. Rietveld-refined XRD patterns for $\mathrm{Cu} / \mathrm{Al} \mathrm{LDH}$ obtained at (a) $\mathrm{pH}=8$ and (b) $\mathrm{pH}=10$.

In all experiments the LDH postsynthesis work-up proceeded using centrifugation, but one sample was isolated using filtration. Their refined XRD patterns are shown in Figure 4. Concerning the unit cell dimensions, no significant differences between these two samples can be perceived (Table S3, supporting information) As evidenced when nitratine phase percentages are compared the centrifuged sample (Figure 4a) it exhibits 5-fold more $\mathrm{NaNO}_{3}$ than the filtrated solid (Figure 4 b), which implies that the postsynthesis work up is an important parameter to be aware of.

To reinforce that postsynthesis steps are very important one last sample was synthesized following the conditions established in the present study; however, this LDH was submitted to washing, using organic solvents (EtOH/Acetone). Its refined XRD measurements are presented in the Figure 5. The calculated unit cell parameters show no significant differences from those previously shown (Table S4, supporting information). In the phase distribution it is clearly observed that the malachite $\%$ dropped from $31.93 \%$ (Figure 4 b) to $10.23 \%$ (Figure 5), increasing LDH \% from $47.92 \%$ to $65.70 \%$.

Besides, the XRD peaks shown in Figure 5 appear wider and less intense than those in Figure $4 b$, for instance. According to the Full Width Half the Maximum (FWHM) criterium used in the Scherrer formula, the mean crystal size evolved from $21 \mathrm{~nm}$ (for samples of Figures 3 and 4 ) to $14 \mathrm{~nm}$, signaling a decrease in crystallinity upon postsynthesis treatment, such as washing with organic solvents.

To evaluate the effect on the borylation reaction, catalytic tests were carried out by using malachite and LDH as catalysts. 
(b)

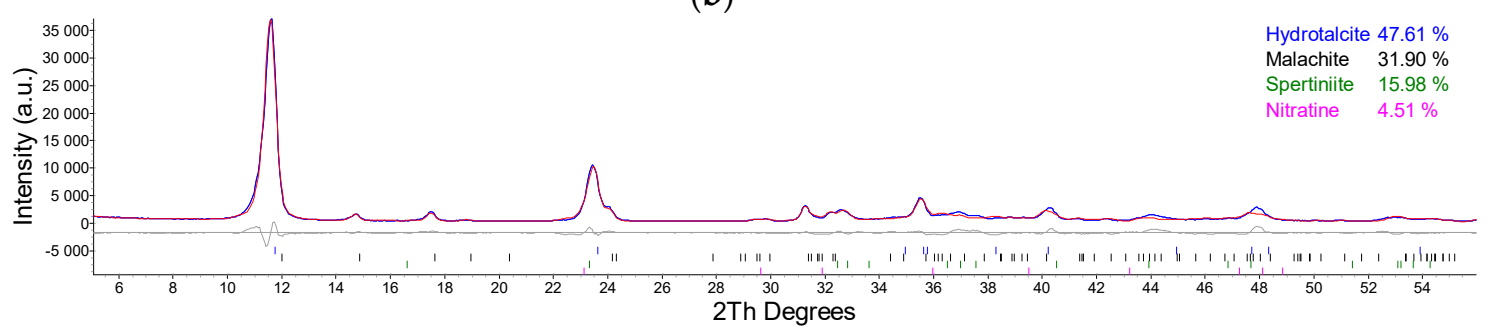

(a)

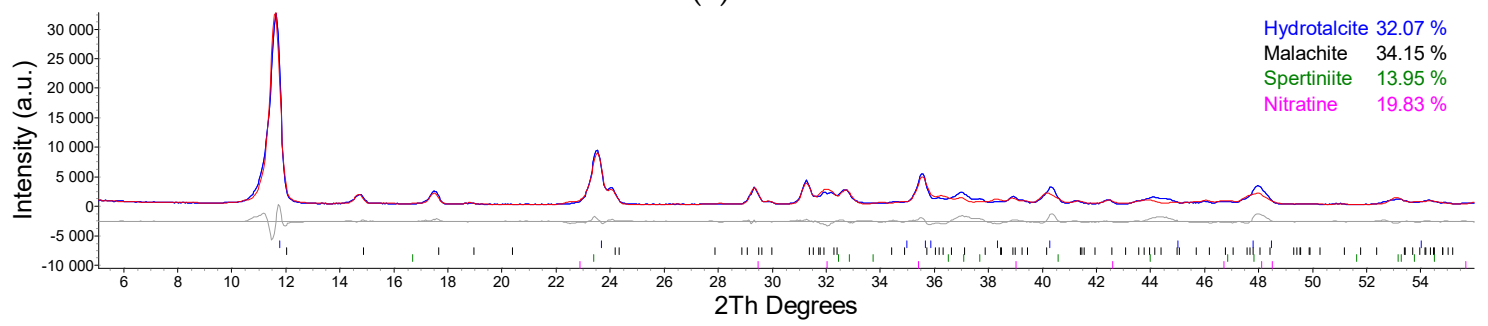

Figure 4. Rietveld-refined $\mathrm{XRD}$ patterns for $\mathrm{Cu} / \mathrm{Al} \mathrm{LDH}$ obtained after (a) centrifugation and (b) filtration.

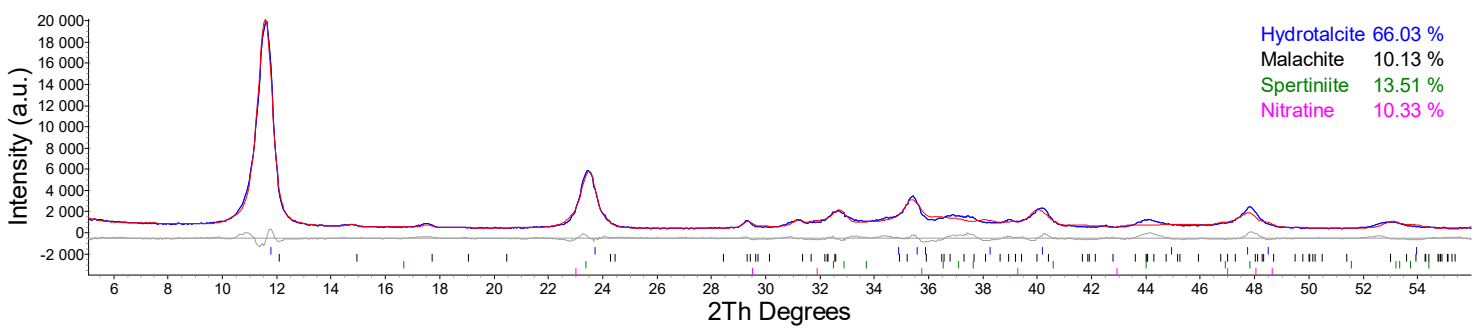

Figure 5. Rietveld-refined XRD pattern for $\mathrm{Cu} / \mathrm{Al} \mathrm{LDH}$ obtained after washing with ethanol and acetone.

\subsection{Synthesis of Aryl Boronic Esters Employing Cu/Al LDH Catalyst}

The reaction between bis(pinacolato)diboron, $\left(\mathrm{B}(\mathrm{pin})_{2}\right)$ and 1-iodo-4-nitrobenzene was taken as a model. Initially, purified $\mathrm{Cu} / \mathrm{Al} \mathrm{LDH}$ and malachite were evaluated as catalysts with acetonitrile as solvent. From these data, it is possible to confirm that malachite did not show catalytic activity towards the borylation reaction. To evaluate the copper loading, we used the LDH composition according to the method previously described by our group [18]. It was observed that both copper-based catalysts were not able to catalyze the reaction (Table 1, entries 1 and 2). Similarly, the use of $\mathrm{Na}_{2} \mathrm{PdCl}_{4}$ as the sole catalyst was ineffective (Table 1, entry 3). Indeed, addition of $\mathrm{CuSO}_{4}$ in combination with $\mathrm{Na}_{2} \mathrm{PdCl}_{4}$ did not react under this condition (Table 1 , entry 4). The comparison of the Pd precursor led us to evaluate a semihomogeneous system composed of palladium nanoparticles (PdNPs) stabilized by cyclodextrins (Table 1, entries 5 and 6). Our research group have already described this catalytic system to the carbon-carbon cross-coupling reactions [19]. However, it was not observed significant conversion even when using acetonitrile. Remarkably, the addition of $2 \mathrm{~mol} \% \mathrm{Na}_{2} \mathrm{PdCl}_{4}$ in the presence of $\mathrm{LDH}$ ( $30 \mathrm{~mol} \% \mathrm{Cu}$ ) allowed a yield of $98 \%$ of the expected product (Table 1, entry 7). Since the positive effect could be related to the LDH structural and compositional properties, we also tested the most common $\mathrm{Mg} / \mathrm{Al} \mathrm{LDH}$ in the presence of $\mathrm{CuSO}_{4}$ and $\mathrm{Na}_{2} \mathrm{PdCl}_{4}$, which rendered a good yield (Table 1, entry 8). Having in mind that the $\mathrm{Cu} / \mathrm{Al} \mathrm{LDH}$ is an anionic exchanger, it has been tested a $\left[\mathrm{PdCl}_{4}\right]^{2-}$ exchanged $\mathrm{Cu} / \mathrm{Al} \mathrm{LDH}$, and surprisingly, the yield obtained was significantly lower, $35 \%$ (Table 1, entry 8 ). 
Table 1. Survey of reaction condition.

\begin{tabular}{ccccc} 
& & & 3 & \\
\hline & & & & \\
\hline
\end{tabular}

${ }^{1}$ Determined by gas chromatography-mass spectrometry (GC-MS); ${ }^{2} \mathrm{Use}$ of $\mathrm{Mg} / \mathrm{Al} \mathrm{LDH}, \mathrm{CuSO}_{4}$ and $\mathrm{Na}_{2} \mathrm{PdCl}_{4} ;{ }^{3}$ $\mathrm{LDH}$ intercalated with $\mathrm{Na}_{2} \mathrm{PdCl}_{4} ;{ }^{4}$ solvent $=\mathrm{THF} ;{ }^{5}$ solvent $=$ dioxane; ${ }^{6}$ Addition of $\mathrm{Cs}_{2} \mathrm{CO}_{3}$.

In order to see the effect of copper in the reaction, we have tested different copper loadings (Table 1, entries 10-12). According to the results, a relatively high loading of copper has shown to be the most adequate for a high conversion (Table 1, entry 7). Similarly, to verify the influence of the Pd loading it was varied from 2 to $0.05 \%$ under the same conditions (Table 1, entries 13-15). In this case, $2 \mathrm{~mol} \% \mathrm{Pd}$ was necessary to keep an acceptable turnover. Analogously to $\mathrm{Cu} \%$, it was observed a direct relationship between the conversion rate and the $\mathrm{Pd} \%$. With the aim of evaluating the effect of noncoordinating solvents, THF and dioxane (Table 1, entries 16 and 17) were also tested under the conditions described in Table 1, entry 3. Surprisingly, no appreciable yield of the product was observed in both cases. Additionally, the use of base hampered the reaction (Table 1, entry 18).

Since the above results demonstrated that the catalytic system based on $\mathrm{Cu} / \mathrm{Al} \mathrm{LDH}$ and $\mathrm{Pd}(\mathrm{II})$ can be efficiently used for the borylation of an aryl iodide under ligand-free conditions, we carried out preliminary reactions with some aryl halides in order to examine its applicability. In this case, we have tested the influence of electron-withdrawing/donating groups substituted in the aromatic core. By considering their comparatively low-cost and availability, we have mainly focused on the evaluation of the reactivity of aryl bromides.

In general, it was possible to note an influence of the electron-withdrawing/ donating capabilities of the substitutional groups. Remarkably, it was evident that the strongly electron-donating amine group did not favor the reaction in both cases (Table 2, entries 1 and 5). In general, the absence of a substituent led to small yields. 
Table 2. Preliminary scope for the borylation reaction catalyzed by $\mathrm{Cu} / \mathrm{Al} \mathrm{LDH}$ and $\mathrm{Na}_{2} \mathrm{PdCl}_{4}{ }^{1}$.

Entry Yield (\%)

${ }^{1}$ Determined by GC-MS.

Encouraged by the preliminary results, we next investigated whether this catalyst could have recycling potential. In such case, it could shed a light on the behavior of $\mathrm{Cu} / \mathrm{Al} \mathrm{LDH}$ as a reservoir or as real catalytically active species. However, attempts to recover the material after reaction work up failed.

\section{Discussion}

Malachite is a common second phase present in Cu/Al LDH synthetic samples [20-26], and it is known to affect the general properties of the LDH, such as its catalytic properties [23-25]. In most cases, it arises from the need to use sodium carbonate as a precipitation co-agent, otherwise LDH is not formed as the majority phase, as observed in Figure 2a. The way the unit cell dimensions obtained for this phase (Table S1, supporting material) evidenced an expanded network in comparison to the carbonate containing LDH phases. This can be understood in terms of attraction electrostatic forces acting between layer and interlayer parts of the material that permit to pack more efficiently when $\mathrm{CO}_{3}{ }^{2-}$ instead of $\mathrm{NO}_{3}{ }^{-}$is used as the intercalated ion. 
Some authors in the literature have tried to eliminate the malachite impurity by a number of different approaches.

Muñoz et al. [23] sought for pure $\mathrm{Cu} / \mathrm{Al} \mathrm{LDH}$ in order to obtain its calcined-oxide derivative to catalyze the reduction of $\mathrm{NO}$ and $\mathrm{CO}$ gases. Through coprecipitation method synthesis they were able to verify that precursors solutions with lower concentrations prevented the formation of malachite, and that the oxide derived from malachite-free LDH showed better catalytic results than the derived from impure $\mathrm{LDH}$. Gao et al. [24] synthetized $\mathrm{Cu} / \mathrm{Zn} / \mathrm{Al} / \mathrm{Zr} \mathrm{LDH}$ in order to obtain its calcined oxide for the catalysis of $\mathrm{CO}_{2}$ hydrogenation, and also found that catalysts with malachite prior to the calcination presented worse catalytic activity than the ones without the contamination. Both Muñoz and Gao agree that higher ratios of $\mathrm{Cu} / \mathrm{Al}$ induce the formation of malachite. Ichikawa et al. [25] tried a different way to obtain noncontaminated $\mathrm{Cu} / \mathrm{Al} \mathrm{LDH}$ : they used a coprecipitation method followed by an aging process at $90^{\circ} \mathrm{C}$ under air bubbling for $1 \mathrm{~h}$. They stated that this process helped to smooth the crystallization process removing the excess of $\mathrm{CO}_{3}{ }^{2-}$ ions. They also found that the calcined oxide derived from the pure $\mathrm{Cu} / \mathrm{Al} \mathrm{LDH}$ was a better catalyst to the conversion of acrylonitrile to acrylamide than the contaminated one. Recently, Qu et al. [26] reported a new mechanochemical synthesis method for $\mathrm{Cu} / \mathrm{Al} \mathrm{LDH}$, in which they dry milled $\mathrm{Cu}_{2}(\mathrm{OH})_{2} \mathrm{CO}_{3}$ and $\mathrm{Al}(\mathrm{OH})_{3}$ at a planetary ball mill for 2 $\mathrm{h}$ at $600 \mathrm{rpm}$, producing an amorphous solid mixture that was treated in aqueous medium at room temperature under magnetic stirring for $4 \mathrm{~h}$, producing a pure $\mathrm{Cu} / \mathrm{Al} \mathrm{LDH}$.

Another important feature is the presence of nitratine $\left(\mathrm{NaNO}_{3}\right)$ in the phase mixture composition after LDH synthesis. Firstly, this phase arises from the combination of sodium of $\mathrm{NaOH}$ solution and nitrate from salt precursors of $\mathrm{Cu}^{2+}$ and $\mathrm{Al}^{3+}$. However, considering sodium nitrate is soluble in aqueous medium, it is not clear how this phase coprecipitates with LDH. Figure 4 gives a hint: the centrifugation process leads to 5 -fold increase of nitratine $\%$ in the phase mixture composition. In addition, Figure 5 points to a decrease by half of this phase percentage guaranteed by washing with $\mathrm{EtOH} /$ Acetone. Therefore, the combined use of filtration and washing in the postsynthesis work-up of $\mathrm{LDH}$ is beneficial for this catalyst.

The catalytic conditions studied for the borylation model reaction were initiated with an activated aryl iodide since electron-withdrawing groups are known for the accelerated effect on the reaction rate [7]. Under the basic conditions of the classical Pd cycle, it is assumed that the higher the Ar-Pd(II)-X electrophilicity, the faster the transmetallation with bisorganodiboron. In fact, the results pointed to a high catalytic conversion by using 4-iodonitrobenzene as an electrophile. To evidence the clean and selective conditions for the borylation reaction, the crude ${ }^{1} \mathrm{H}$ NMR spectrum of 3 is presented in the Supporting Information. A relatively high copper loading was, however, necessary to increase the substrate conversion. As pointed out, this fact has already been observed by Ratnyom [12] and other groups [13] but involving a typically homogeneous catalytic system based on $\mathrm{Cu}$ or Pd/Cu combined with phosphines. Regarding the usual organometallic mechanism, it is interesting to note that the $\mathrm{LDH}$ surface is possibly responsible for the presence of basic species involved in the preactivation step. The addition of base, however, was detrimental to the reaction, suggesting a partial decomposition of the LDH structure.

Even though the cooperative catalysis of $\mathrm{Pd}$ and $\mathrm{Cu}$ was already reported in some recent works, the ligand-free condition has been scarcely explored mostly because of the difficult electronic tuning towards the transmetallation step even though the soft coordination of acetonitrile cannot be ruled out. However, the surprising fact here is related to the superior activity of a heterogeneous layered $\mathrm{Cu}$ matrix, which allowed high substrate conversion and product selectivity in the reaction model. In detriment, common copper salts, such as the basic copper carbonate (malachite), were ineffective under the same conditions, indicating that the chemical environmental around copper is decisive to the reaction outcome even in the presence of palladium. This fact could be reinforced when testing $\mathrm{Mg} / \mathrm{Al}$ $\mathrm{LDH}$ in the presence of $\mathrm{CuSO}_{4}$ and $\mathrm{Na}_{2} \mathrm{PdCl}_{4}$ that resulted in an inferior product yield compared to the same catalytic conditions by using the $\mathrm{Cu} / \mathrm{Al}$ matrix. 
In addition, the preliminary scope of the method showed an unclear electronic effect of substituents: apparently, the reaction is favored by both electron-donating and -withdrawing groups but, intriguingly, it was not the case for the amine substituent. It is conceivable that a hybrid mechanism is operative with the moderate to low yields of $\alpha$-naphtyl, 4-bromobenzyl and phenyl bromides arising from a predominant oxidative addition modulation. However, the low reactivity of bromobenzene was intriguing. We presume the occurrence of possible alternative pathways (e.g., Ullmann-type reaction and hydrodehalogenation) in minor extension but the solubility factor cannot be ruled out. Indeed, the role of LDH matrix as a catalytic reservoir of active $\mathrm{Cu}$ species can be considered based on experiments with coordinating solvents [27]. According to the frustrated catalyst recycling attempts, it is also possible that acetonitrile act as a moderate LDH exfoliation agent. On the other hand, the effect of $\mathrm{PdCl}_{4}{ }^{2-}$ intercalation in $\mathrm{LDH}$ seems to slow down the possible $\mathrm{Pd}(\mathrm{II})$ reduction. Lastly, (Bpin) $)_{2}$ seems to be involved in the reduction of $\operatorname{Pd}(\mathrm{II})$ species, as suggested by the solution darkening according to visual inspection.

Taken together, these results suggest that a synergic effect between the $\mathrm{Cu}(\mathrm{II})$ and $\mathrm{Pd}(0)$ species can arise from a combination of factors related to the electronic effects on substrate along with the chemical environment of both metals.

A schematic view containing some of these effects is shown in Scheme 1.
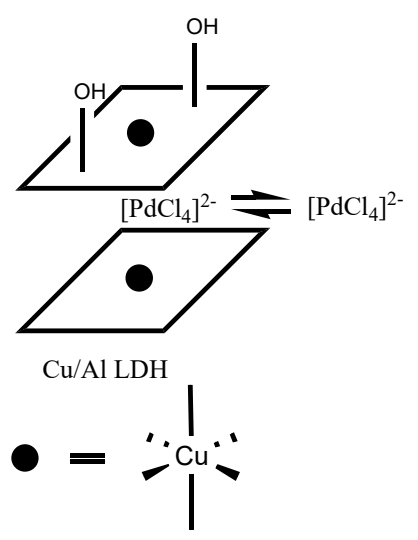

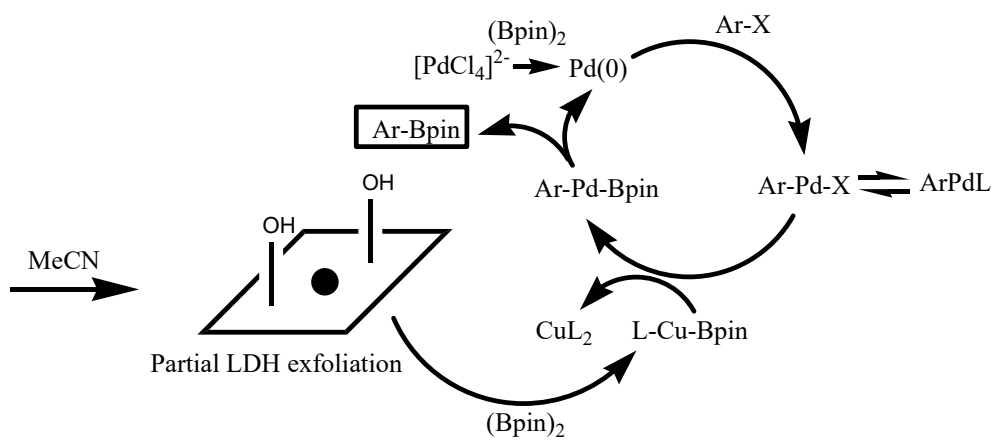

Scheme 1. Proposed mechanism for the Pd and Cu-catalyzed aryl borylation in the presence of LDH.

\section{Materials and Methods}

All the reactants and solvents in this work were commercially acquired and used without previous purification.

The powder X-ray diffractograms were recorded by a diffractometer Panalytical X'Pert PRO MPD (Malvern Panalytical Ltd., Royston, United Kingdom), with generator of Cu X-ray $(\lambda=1.5418$ Á), line focus $(1.8 \mathrm{~kW})$, universal Theta-2Theta goniometer with $240 \mathrm{~mm}$ radius, divergence slit fixed $\frac{1}{2}^{\circ}$, flat-diffracted beam monochromator, and proportional detector Xe with $40 \mathrm{kV}$ of tension and $40 \mathrm{~mA}$ of current in the $\mathrm{X}$-ray tube. The samples were analyzed self-supported in aluminum sample holder and used under the Bragg-Brentano geometry; it used ranges between $5^{\circ}<2 \theta<70^{\circ}$, with $0.05^{\circ}$ step and $2.5 \mathrm{~s}$ per step.

The calculation based on the Rietveld Refinement applied in this work, through the program TOPAS academic V5.0 (Coelho Software, Brisbane, Australia), was based on the Fundamental Parameters Approach, based on the instrumental parameters with background correction. If necessary, the following parameters were refined; unit cell dimensions, sample height displacement, zero-shift, weight fraction (scaling), preferred orientation, atomic species/substitutions, atomic coordinates, site occupancies, thermal displacement parameters, crystallite size, and lattice strain. 
All the organic products were characterized by ${ }^{1} \mathrm{H}$ and ${ }^{13} \mathrm{C}$ NMR spectroscopy (Bruker Analytics, Berlin, Germany).

\subsection{Synthesis of the Cu/Al Layered Double Hydroxides}

The $\mathrm{Cu} / \mathrm{Al}$ layered double hydroxides $(\mathrm{Cu} / \mathrm{Al} \mathrm{LDH})$ and $\mathrm{Cu}_{4} \mathrm{Al}_{2}(\mathrm{OH})_{12} \mathrm{CO}_{3} \cdot 4 \mathrm{H}_{2} \mathrm{O}$, were synthetized using a constant $\mathrm{pH}$ method: one aqueous solution of $\mathrm{Cu}\left(\mathrm{NO}_{3}\right)_{2} \cdot 3 \mathrm{H}_{2} \mathrm{O}$ $\left(0.225 \mathrm{~mol} \cdot \mathrm{L}^{-1}\right)$ and $\mathrm{Al}\left(\mathrm{NO}_{3}\right)_{3} \cdot 9 \mathrm{H}_{2} \mathrm{O}\left(0.075 \mathrm{~mol} \cdot \mathrm{L}^{-1}\right)$ and other of $\mathrm{NaOH}\left(0.50 \mathrm{~mol} \cdot \mathrm{L}^{-1}\right)$ and, alternatively, $\mathrm{Na}_{2} \mathrm{CO}_{3}\left(0.15 \mathrm{~mol} \cdot \mathrm{L}^{-1}\right)$, were added $(40 \mathrm{~mL}$ each) simultaneously by continuous dropping to $40 \mathrm{~mL}$ of a $\mathrm{NaOH}$ solution $(\mathrm{pH}=8$ or 10), under magnetic stirring at room temperature. The $\mathrm{pH}$ was maintained during the process. A blue slurry was formed, which was then filtrated or centrifuged and dried at room temperature. The filtrated material was alternatively washed with ethanol:acetone 1:1 volume mixture.

\subsection{Synthesis of Boronic Esters Employing Palladium Nanoparticles}

The synthesis of PdNPs followed method described by Senra et al. [19], Scheme 2. At first, $1 \mathrm{~mL}$ of a $\mathrm{Na}_{2} \mathrm{PdCl}_{4} 0.005 \mathrm{~mol} \cdot \mathrm{L}^{-1}$ aqueous solution was mixed with $69 \mathrm{mg}$ of $\beta$-cyclodextrin in a $10 \mathrm{~mL}$ glass flask and the mixture was kept at $70{ }^{\circ} \mathrm{C}$ for $1 \mathrm{~h}$ under magnetic stirring. Then, it was added to the flask $0.25 \mathrm{mmol}$ of 1-bromo-4-methoxybenzene, $0.25 \mathrm{mmol}$ de bis(pinacolato)diboron, $0.375 \mathrm{mmol}$ of $\mathrm{K}_{2} \mathrm{CO}_{3}$, and $2 \mathrm{~mL}$ of solvent (ethanol $/ \mathrm{H}_{2} \mathrm{O} 50 \%$ or acetonitrile). The system was kept at $70{ }^{\circ} \mathrm{C}$ for $24 \mathrm{~h}$, and then the reaction mixture was extracted with dichloromethane and $\mathrm{NaCl}$ aqueous saturated solution (1:1). After the extraction, the mixture was dried with anhydrous sodium sulfate and evaporated under reduced pressure.

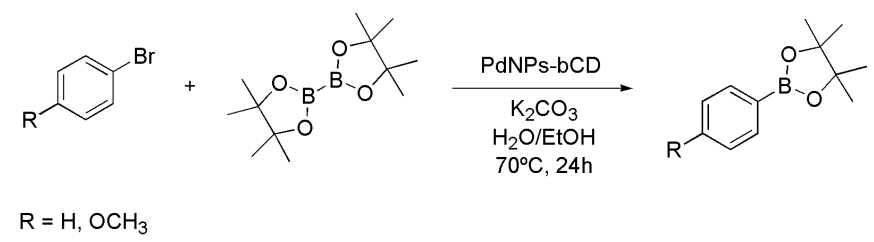

Scheme 2. Preliminary reaction.

\subsection{Synthesis of Boronic Esters Employing $\mathrm{Na}_{2} \mathrm{PdCl}_{4} / \mathrm{Cu} / \mathrm{Al} \mathrm{LDH}$}

Into a 5-mL screw cap flask was added $0.9 \mathrm{mmol}$ de bis(pinacolato)diboron, $0.6 \mathrm{mmol}$ de 1-iodo-4-nitrobenzene, $2 \mathrm{~mL}$ of solvent, and $0.15 \mathrm{mmol}(\mathrm{Cu})$ of $\mathrm{LDH} / \mathrm{Pd}$ or $0.15 \mathrm{mmol}(\mathrm{Cu})$ of $\mathrm{Cu} / \mathrm{Al}$ $\mathrm{LDH}$ and $2 \mathrm{~mL}$ of $\mathrm{Na}_{2} \mathrm{PdCl}_{4} 0.005 \mathrm{~mol} \cdot \mathrm{L}^{-1}$ aqueous solution, Scheme 3 . In the latter, the percentage of palladium varied from $2 \%$ to $0.5 \%$. The system was kept at $70{ }^{\circ} \mathrm{C}$ for $24 \mathrm{~h}$ under magnetic stirring, and its extraction was done as described in Supporting Information.

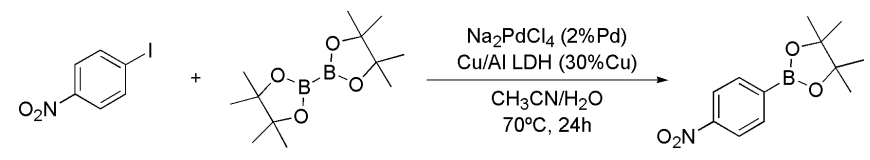

Scheme 3. Model reaction.

\section{Conclusions}

$\mathrm{Cu} / \mathrm{Al} \mathrm{LDH}$ had some synthesis parameters evaluated in order to produce the least quantity of by-products. For such material, the list of contaminants includes the mineral-like phases malachite, spertiniite, and nitratine. The catalytic system based on the least-contaminated LDH heterogeneous matrix and aqueous $\mathrm{Na}_{2} \mathrm{PdCl}_{4}$, under ligand-free conditions, showed efficient catalytic properties in the borylation reactions by using bis(pinacolato)diboron as boron precursor. This catalyst system can be a promising low-cost alternative for use in classical homogeneous phosphine-based systems. 
Additional experiments to investigate the possible reaction intermediates and their correlation with the LDH structure are under investigation and will be reported in due course.

Supplementary Materials: The following are available online at http:/ /www.mdpi.com/2073-4344/9/4/302/s1: Figure S1: ${ }^{1} \mathrm{H}$ NMR of 3, Figure S2: ${ }^{13} \mathrm{C}$ NMR of 3, Figure S3: ${ }^{1} \mathrm{H}$ NMR of 4, Figure S4: ${ }^{13} \mathrm{C}$ NMR of 4, Figure S5: ${ }^{1} \mathrm{H}$ NMR of 6, Figure S6: ${ }^{13} \mathrm{C}$ NMR of 6, Figure S7: ${ }^{1} \mathrm{H}$ NMR of 7, Figure S8: ${ }^{13} \mathrm{C}$ NMR of 7, Figure S9: ${ }^{1} \mathrm{H}$ NMR of 8, Figure S10: ${ }^{13} \mathrm{C}$ NMR of 8, Figure S11: ${ }^{1} \mathrm{H}$ NMR of 9, Figure S12: ${ }^{13} \mathrm{C}$ NMR of 9).

Author Contributions: L.C.L.L.F.S. conducted all the borylation reactions. V.A.N. prepared the catalysts. V.S.R. and J.B.d.C. conducted the XRD analysis and the Rietveld refinements. R.S.F.S. and A.A.d.S. conducted the product characterization. L.F.B.M. and J.D.S. supervised the work and wrote the paper.

Funding: This study was financed in part by the Coordenação de Aperfeiçoamento de Pessoal de Nível Superior-Brasil (CAPES), Finance Code 001. All authors acknowledge the financial support by CNPq and FAPERJ. Specifically, L.F.B.M. would like to thank the funding from CNPq, Universal project code 425613/2016-0, and from FAPERJ, Jovem Cientista do Nosso Estado project code E-26/203.212/2017.

Acknowledgments: The authors thank CBPF (Centro Brasileiro de Pesquisas Físicas), UFRJ and UERJ for the analytical support.

Conflicts of Interest: The authors declare no conflicts of interest.

\section{References}

1. Wu, X.; Chen, X.X.; Jiang, Y.B. Recent advances in boronic acid-based optical chemosensors. Analyst 2017, 142, 1403-1414. [CrossRef] [PubMed]

2. Roll, M.F. Ionic borohydride clusters for the next generation of boron thin-films: Nano-building blocks for electrochemical and refractory materials. J. Mater. Res. 2016, 31, 2736-2748. [CrossRef]

3. Pisarev, M.A.; Dagrosa, M.A.; Juvenal, G.J. Boron neutron capture therapy in cancer: Past, present and future. Arq. Bras. Endocrinol. Metab. 2007, 51, 852-856. [CrossRef]

4. Hall, D.G. Boronic Acids; Wiley: Weinheim, Germany, 2005.

5. Cheng, Y.; Mgck-Lichtenfeld, C.; Studer, A. Metal-Free Radical Borylation of Alkyl and Aryl Iodides. Angew. Chem. Int. Ed. 2018, 57, 16832-16836. [CrossRef]

6. Zhang, L.; Jiao, L. Pyridine-Catalyzed Radical Borylation of Aryl Halides. J. Am. Chem. Soc. 2017, 139, 607-610. [CrossRef]

7. Chow, W.K.; Yuen, O.Y.; Choy, P.Y.; So, C.M.; Lau, C.P.; Wong, W.T.; Kwong, F.Y. A decade advancement of transition metal-catalyzed borylation of aryl halides and sulfonates. RSC Adv. 2013, 3, 12518-12539. [CrossRef]

8. Ishiyama, T.; Murata, M.; Miyaura, N. Palladium(0)-Catalyzed Cross-Coupling Reaction of Alkoxydiboron with Haloarenes: A Direct Procedure for Arylboronic Esters. J. Org. Chem. 1995, 60, 7508-7510. [CrossRef]

9. Avitia, B.; MacIntosh, E.; Muhia, S.; Kelson, E. Single-flask preparation of polyazatriaryl ligands by a sequential borylation/Suzuki-Miyaura coupling. Tetrahedron Lett. 2011, 52, 1631-1634. [CrossRef]

10. Xie, D.; Rong, L.; Zhang, D.; Hu, J.; Xiao, D.; Li, X.; Xiang, Y.; Jin, W. Palladium-catalyzed borylation of $\mathrm{m}$-dibromobenzene derivative and its applications in one-pot tandem Suzuki-Miyaura arenes synthesis. Tetrahedron 2015, 71, 8871-8875. [CrossRef]

11. Hemming, D.; Fritzemeier, R.; Westcott, S.A.; Santos, W.L.; Steel, P.G. Copper-boryl mediated organic synthesis. Chem. Soc. Rev. 2018, 47, 7477-7494. [CrossRef]

12. Ratniyom, J.; Dechnarong, N.; Yotphan, S.; Kiatisevi, S. Convenient Synthesis of Arylboronates through a Synergistic Pd/Cu-Catalyzed Miyaura Borylation Reaction under Atmospheric Conditions. Eur. J. Org. Chem. 2014, 7, 1381-1385. [CrossRef]

13. Mills, S.J.; Christy, A.G.; Génin, J.-M.R.; Kameda, T.; Colombo, F. Nomenclature of the hydrotalcite supergroup: Natural layered double hydroxides. Miner. Mag. 2012, 75, 1289-1336. [CrossRef]

14. Vaccari, A. Preparation and catalytic properties of cationic and anionic clays. Catal. Today 1998, 41, 53-71. [CrossRef]

15. Béres, A.; Pálinkó, I.; Kiricsi, I.; Nagy, J.B.; Kiyozumi, Y.; Mizukami, F. Layered double hydroxides and their pillared derivatives-Materials for solid base catalysis; synthesis and characterization. App. Catal. A Gen. 1999, 182, 237-247. [CrossRef] 
16. Silva, A.C.; Senra, J.D.; de Souza, A.L.F.; Malta, L.F.B. A Ternary Catalytic System for the Room Temperature Suzuki-Miyaura Reaction in Water. Sci. World J. 2013. [CrossRef]

17. Sreedhar, B.; Arundhathi, R.; Reddy, P.L.; Reddy, M.A.; Kantam, M.L. Cu-Al Hydrotalcite: An efficient and reusable ligant-free catalyst for the coupling of aryl chlorides with aliphatic, aromatic, and $\mathrm{N}(\mathrm{H})$-heterocyclic amines. Synthesis 2009, 15, 2517-2522. [CrossRef]

18. Neves, V.A.; Costa, M.V.; Senra, J.D.; Aguiar, L.C.S.; Malta, L.F.B. Thermal behavior of LDH 2CuAl.CO3 and 2CuAl.CO3/Pd. J. Therm. Anal. Calorim. 2017, 130, 689-694. [CrossRef]

19. Senra, J.D.; Malta, L.F.B.; Michel, R.C.; Cordeiro, Y.; Simão, R.A.; Simas, A.B.C.; Aguiar, L.C.S. Hydrophilic cyclodextrin protected Pd nanoclusters: Insights into their size control and host-guest behavior. J. Mater. Chem. 2011, 21, 13516-13523. [CrossRef]

20. Segal, S.R.; Carrado, K.A.; Marshall, C.L.; Anderson, K.B. Catalytic decomposition of alcohols, including ethanol, for in situ $\mathrm{H}_{2}$ generation in a fuel stream using a layered double hydroxide-derived catalyst. Appl. Catal. A Gen. 2003, 248, 33-45. [CrossRef]

21. Manivannan, R.; Pandurangan, A. Formation of ethyl benzene and styrene by side chain methylation of toluene over calcined LDHs. Appl. Clay Sci. 2009, 44, 137-143. [CrossRef]

22. Lwin, Y.; Yarmo, M.A.; Yaakob, Z.; Mohamad, A.B.; Daud, W.R.W. Synthesis and characterization of Cu/Al layered double hydroxides. Mater. Res. Bull. 2001, 36, 193-198. [CrossRef]

23. Muñoz, V.; Zotin, F.M.Z.; Palacio, L.A. Copper-aluminum hydrotalcite type precursors for $\mathrm{NO}_{\mathrm{x}}$ abatement. Catal. Today 2015, 250, 173-179. [CrossRef]

24. Gao, P.; Xie, R.; Wang, H.; Zhong, L.; Xia, L.; Zhang, Z.; Wei, W.; Sun, Y. Cu/Zn/Al/Zr catalyst via phase-pure hydrotalcite-like compounds for methanol synthesis from carbon dioxide. J. $\mathrm{CO}_{2}$ Util. 2015, 11, 41-48. [CrossRef]

25. Ichikawa, S.; Miyazoe, S.; Matsuoka, O. A highly efficient $\mathrm{Cu} / \mathrm{Al}(\mathrm{OH})_{3}$ catalyst for the hydration of acrylonitrile to acrylamide. Chem. Lett. 2011, 40,512-514. [CrossRef]

26. Qu, J.; He, X.; Chen, M.; Hu, H.; Zhang, Q.; Liu, X. Mechanochemical synthesis of Cu/Al and methyl orange intercalated Cu/Al layered double hydroxides. Mater. Chem. Phys. 2017, 191, 173-180. [CrossRef]

27. Neves, V.A. Nanostructured Materials Based on Cu/Al Layered Double Hydroxides, Pd and Cyclodextrin as Catalysts for Cross-Coupling Reactions. Master's Thesis, Federal University of Rio de Janeiro, Rio de Janeiro, Brazil, 2018.

(C) 2019 by the authors. Licensee MDPI, Basel, Switzerland. This article is an open access article distributed under the terms and conditions of the Creative Commons Attribution (CC BY) license (http:/ / creativecommons.org/licenses/by/4.0/). 